\title{
Patrimônio histórico-cultural: critérios para tombamento de bibliotecas pelo
} IPHAN

\author{
Eduardo Ismael Murguia
}

\begin{abstract}
Professor do Departamento e do Curso de Pósgraduação em Ciência da Informação da FFC UNESP - Marília.
\end{abstract}

Silvia Nathaly Yassuda

\begin{abstract}
Mestranda do Curso de Pós-graduação em Ciência da Informação da FFC UNESP - Marília
\end{abstract}

Em razão do conteúdo informacional que preservam, as bibliotecas são consideradas grandes centros de memória. Tal fato motivou uma análise das bibliotecas tombadas pelo Iphan, com os seguintes objetivos: iniciar uma reflexão sobre suas peculiaridades enquanto patrimônio histórico-cultural, conhecer as justificativas oficiais que levaram ao tombamento, e discriminar o tombamento do prédio e/ou da coleção. Detectou-se que apenas o monumento arquitetônico das bibliotecas foi o critério priorizado, e que o tombamento delas foi apenas conseqüência do tombamento do edifício que as abrigava.

Palavras-chave: Patrimônio Histórico; Biblioteca; Coleções de Obras Raras

\section{Historical-cultural heritage: criteria for libraries listed by IPHAN.}

\begin{abstract}
Because of the information content that they hold libraries are considered important centers of memory. Thus, in order to start a reflection on the peculiarities of libraries as a cultural heritage an analysis of libraries listed by IPHAN was undertaken. Also, we attempted to recognize the official justifications that lead the buildings or the collections to be listed. Questionnaires were sent and applied. It was detected that the criteria for the listing process were primarily historical and architectural values, and the collection was listed as a consequence.
\end{abstract}




\section{Keywords: Historical Heritage; Library; Special Collections}

Recebido em 13.06.2007 Aceito em 01.10.2007

\section{Introdução}

As bibliotecas, na atualidade, desempenham diferentes papéis na sociedade. Neste trabalho, dar-se-á especial destaque à biblioteca como instituição de preservação dos registros do passado deixados pelo homem. Daí poder-se chamá-las de centro de memória, pois guardam e disponibilizam documentos nos mais variados tipos de suportes, onde estão registradas informações que representam o passado ou, mais especificamente, a memória coletiva de determinados grupos de pessoas ou mesmo de uma nação, como no caso das Bibliotecas Nacionais.

Além da coleção da biblioteca, o monumento arquitetônico, ou seja, o prédio, também é representativo da memória. Os detalhes da construção, sua localização, o período em que foi construído, as múltiplas funções que desempenham, são especificidades que podem justificar a possível preservação da construção.

Abordar a questão da preservação não é uma tarefa fácil. Os princípios que guiam e sustentam essa atividade sofreram, e sofrem, constantes modificações ao longo do tempo. A Modernidade, por exemplo, propiciou modificações sem fim, produto da própria lógica do sistema econômico. Assim, a sociedade, através dos seus órgãos representativos, cria leis que preservam edificações, documentos e objetos considerados significativos para sua identidade, como uma forma de salvaguardar os vestígios do passado.

Dentre os meios legais de proteção ao patrimônio, destaca-se o tombamento. Com ele, é possível preservar bens de valor histórico, cultural, arquitetônico, ambiental e afetivo, impedindo que sejam destruídos ou descaracterizados.

Em consonância com os dados acima citados, este trabalho tem os seguintes objetivos: iniciar uma pesquisa que nos leve a pensar as bibliotecas enquanto patrimônio histórico-cultural, conhecer as justificativas oficiais que levaram ao tombamento das bibliotecas e de suas coleções e, por fim, discernir as diferenças do tombamento enquanto prédio e enquanto coleção, pois parte-se do princípio de que a coleção materializa o fim último da biblioteca, que é a informação.

Para desenvolver tal pesquisa, seguimos as seguintes etapas: levantamento bibliográfico, levantamento e seleção das bibliotecas a serem analisadas, envio de questionários às bibliotecas e coleções bibliográficas tombadas, pesquisa nos sites pertinentes ao tema, consulta aos processos de tombamento, transcrição das informações referentes ao tombamento contidas nos respectivos processos das bibliotecas e, por fim, análise e discussão dos dados obtidos. 


\section{Patrimônio histórico e artístico}

O termo patrimônio originou-se da palavra pater, que significa pai ou paterno. O patrimônio representava, como ainda representa, os bens de herança que são transmitidos aos filhos. Ao longo dos tempos o significado do termo patrimônio estendeu-se aos bens de determinados grupos sociais, que eram passados para as gerações futuras como forma de transmitir seus conhecimentos e seu poder de dominação. Entre esses grupos estava a Igreja, que durante a Idade Média possuía objetos de altíssimo valor material, representativos da fé cristã. Muitos desses objetos formavam parte dos tesouros da Igreja e outros eram passados de geração a geração como verdadeiras relíquias. Além dos objetos, observa-se que os cultos, as vestimentas, as cerimônias, foram preservados pela Igreja, mantendo-se, dessa forma, o patrimônio da tradição cristã.

Na mesma época a aristocracia feudal também se preocupava com a preservação de seus bens: "Na Idade Média a aristocracia projetava nos seus castelos e em outras representações de suas linhagens um sentido de símbolos de sua continuidade, e, por essa razão, esses bens se tornavam também objeto de preservação" (FONSECA, 1997, p. 53). No entanto, notamos que esses dois grupos sociais tinham por intuito a preservação de bens, mesmo que culturais, em benefício próprio, e não em benefício de uma coletividade.

A prática da preservação encontrou nos antiquários seus primeiros representantes. Eles eram humanistas eruditos que pesquisavam as antigas civilizações. Com eles é possível perceber um deslocamento da função dos objetos. Segundo Choay (2001), os antiquários acreditavam mais no estudo e análise dos objetos deixados pelas antigas civilizações do que nas palavras dos autores que as relatavam. Para eles, os objetos e monumentos eram uma prova viva e não tinham como alterar ou omitir informações. Além disso, era comum a troca de informações e objetos entre os antiquários.

A atividade dos antiquários era vista como uma reação contra o vandalismo religioso da Reforma na Inglaterra, e perdurou até o século XX. Já na França, a partir da Revolução, a atuação dos antiquários entrou em declínio quando o Estado assumiu e passou a centralizar as atividades preservacionistas. A partir desse momento se iniciou a proteção legal de bens culturais, permitindo, assim, que se ampliasse a noção de patrimônio histórico como relíquias herdadas por toda uma geração de pessoas e não mais por grupos sociais isolados. Por conseguinte, os bens estariam disponíveis ao uso e benefício do povo. A partir de então, a conservação baseada nas práticas particulares dos antiquários deu lugar a uma atividade do Estado como protetor dos bens gerais.

Com a Revolução Francesa os bens culturais adquiriram uma identidade nacional, e foram apoiados por uma legislação específica. Pela primeira vez surge a função social da preservação do patrimônio: 
[...] a efetivação da preservação dos bens culturais só se encontra socialmente definida, ou seja, só aparece como fato social, quando o Estado assume a sua proteção e, através da ordenação jurídica, os institui e delimita oficialmente enquanto bem cultural, regulamentando o seu uso, a finalidade e o caráter desses bens dentro de leis específicas de propriedade, zoneamento, uso e ocupação do solo. (MILET, 1988 apud FONSECA, 1997, p. 54)

Segundo Choay (2001), durante a Revolução Francesa os bens do clero e da nobreza foram confiscados e seu destino ficou a cargo do Comitê de Instrução Pública. Os bens móveis, representados por objetos de arte em sua grande maioria, foram alojados em museus, com o objetivo de servir à instrução da nação; e os bens imóveis, como igrejas, castelos e residências, tiveram uma nova utilização.

Foi necessário que se elaborasse um método para preparar o inventário dos bens herdados e definisse regras para administrá-los. Criou-se então uma comissão intitulada "dos Monumentos", responsável pelo tombamento, e que dividia em categorias os bens recuperados pela Nação. Em seguida os bens eram inventariados, discriminando-se seu estado de conservação. Finalmente eram protegidos e colocados fora de circulação, reunidos em depósitos.

Apesar das grandes perdas e da fragilidade da gestão preservacionista, após a Revolução Francesa as mudanças de mentalidade começaram a se manifestar. A partir da segunda década do século XIX o valor artístico dos monumentos do passado foi, pela primeira vez, reconhecido como critério para preservação.

No Brasil, o patrimônio histórico e artístico nacional foi citado pela primeira vez, como objeto de proteção obrigatória pelo poder público, na Constituição de 1934, sendo que cabia à União e aos Estados proteger as belezas naturais e os monumentos de valor histórico ou artístico. Mais tarde, o Decreto-lei no 25 de 30.11.37, primeira lei nacional de proteção ao patrimônio no Brasil, oficializa o resguardo dos nossos bens culturais.

Atualmente, o alerta para a perda de inúmeros bens da nação, incluindo o meio ambiente, os costumes, as línguas e as tradições, é feito constantemente. Segundo Possamai (2000, p. 16):

O patrimônio hoje é preocupação de um número expressivo de países em todo o mundo, reunindo profissionais de diversas áreas, que compartilham os postulados técnicos e teóricos relacionados a essas tarefas. As discussões sobre o patrimônio abrangem um grande número de aspectos, que vão desde a identificação de um conjunto cada vez mais abrangente de bens culturais - incluindo não apenas monumentos, mas também os bens natural e etnológico - até o gerenciamento e sustentabilidade dos patrimônios junto às comunidades locais.

Existe, hoje, uma preocupação no que se refere ao reconhecimento dos cidadãos pelo bem tombado. Segundo Cunha (1992), em nosso país 
muitos ainda relacionam a ação de preservação patrimonial a uma atividade meramente acadêmica, que pouco tem a ver com a luta pela democracia e os direitos de cidadania, o que tem dificultado a divulgação das ações de preservação e a participação mais ativa da população. Dessa forma, mister se faz reconhecer que é fundamental haver um reconhecimento da sociedade pelo bem tombado, que é necessário que ela se identifique com ele.

Como observado, existe uma relação muito estreita entre a preservação de bens culturais e a cidadania. O direito ao passado, à memória, é um de todos os cidadãos, independente de classe social, raça, cultura. É, enfim, o exercício da cidadania se fazendo presente em cada monumento tombado, em cada objeto preservado, em cada atividade cultural resguardada. Fenelon (1992, p.31) propõe uma reflexão sobre o verdadeiro sentido de se preservar:

Quando propomos o debate e a reflexão sobre as políticas de patrimônio histórico, queremos tratá-lo não apenas no âmbito restrito das técnicas de intervenção ou dos critérios de identificação e preservação e seus conceitos operacionais. Para além desses aspectos, é preciso politizar o tema, reconhecendo as condições históricas em que se forjaram muitas das suas premissas - e articulando-as com as lutas pela qualidade de vida, pela preservação do meio ambiente, pelos direitos à pluralidade e sobretudo pelo direito à cidadania cultural. Com isso esperamos retomar um sentido de patrimônio histórico que nos permita entendê-lo como prática social e cultural de diversos e múltiplos agentes.

Até agora se viu a maneira pela qual se preserva o patrimônio, as idéias que sustentam essa atividade social e suas modificações ao longo do tempo. Proceder-se-á, agora, a uma análise para ver de que maneira essas idéias se expressam e se objetivam por meio das leis.

\section{A legislação patrimonial}

A inquietação quanto à preservação dos bens culturais das nações desencadeou a criação de leis que garantissem sua proteção. Um encontro de representações de diversos países, ocorrido em Atenas no mês de outubro de 1931, reuniu profissionais e entidades preocupados com a preservação dos bens culturais, surgindo nesse momento a "Carta de Atenas". Tal documento foi a primeira manifestação oficial e internacional de apoio à proteção de bens culturais no mundo, promovendo um amplo movimento internacional.

Em maio de 1964 promoveu-se em Veneza um outro encontro de grande importância, o II Congresso Internacional de Arquitetos e Técnicos dos Monumentos Históricos. O resultado desse encontro foi a criação da "Carta de Veneza", também de grande relevância para as políticas de preservação mundiais. Mais tarde, em novembro de 1972 , foi realizada a Convenção de Paris, também conhecida como Convenção do Patrimônio Mundial, tamanha sua repercussão.

No Brasil, a primeira lei de proteção ao patrimônio histórico e artístico nacional foi o Decreto Lei n025 de 30 de novembro de 1937. Esse 
decreto vigora até os dias atuais e foi complementado por leis subseqüentes, sendo elaborado por Rodrigo Melo Franco de Andrade, que na época respondia pela direção do Iphan.

Em 1970, o Ministério da Educação e Cultura se reuniu em Brasília, convocando os secretários estaduais de Educação e Cultura, governadores, representantes de governadores, prefeitos de cidades, presidentes e representantes de instituições culturais, a fim de que fossem estudadas medidas complementares de proteção e valorização do patrimônio cultural do Brasil, nascendo desse encontro o "Compromisso de Brasília". Em 1971 o Ministério da Cultura promoveu um novo encontro, nos mesmos moldes do de Brasília, agora em Salvador, a fim de complementar as medidas necessárias à defesa do patrimônio histórico, artístico, arqueológico e natural do país.

Segundo Rhoden (2000), esses dois compromissos vinham atender às recomendações contidas em documentos internacionais, como o da Conferência da Unesco, de Paris, de novembro de 1968, e o da Organização dos Estados Americanos - OEA, denominado "Normas de Quito", de 1967.

A proteção e preservação legal de um bem cultural, segundo a legislação vigente em nosso país, é requerida por meio do tombamento. Segundo o Iphan, tombamento pode ser entendido como:

[...] um ato administrativo realizado pelo Poder Público com o objetivo de preservar, por intermédio da aplicação de legislação específica, bens de valor histórico, cultural, arquitetônico, ambiental e também de valor afetivo para a população, impedindo que venham a ser destruídos ou descaracterizados. (INSTITUTO DO PATRIMÔNIO HISTÓRICO E ARTÍSTICO NACIONAL - IPHAN, 2004)

O tombamento pode ser aplicado a bens móveis (objetos) ou imóveis (prédios), de interesse cultural ou ambiental. Pode ser feito pela União, pelo Governo Estadual ou pelas administrações municipais. Um bem tombado não precisa ser desapropriado; além disso, ele ainda pode ser vendido ou alugado, contanto que continue sendo preservado. A solicitação do tombamento aos órgãos responsáveis pode ser feita por qualquer pessoa física ou jurídica.

Já o patrimônio imaterial foi recentemente reconhecido como bem cultural a ser preservado. Ele é protegido por meio do Decreto no 3.551 de 4 de agosto de 2000. Festas populares, expressões artísticas, conhecimentos tradicionais, lendas e mitos, se enquadram na relação de bens de natureza imaterial assegurados por este decreto.

O primeiro passo para se requerer um tombamento consiste no pedido de abertura de processo, por iniciativa de qualquer cidadão ou instituição pública. O processo passa por uma avaliação técnica e posteriormente é submetido à deliberação dos órgãos responsáveis pela preservação. Caso seja aprovado, é expedida uma notificação ao seu proprietário. A partir desse momento, o bem já se encontra protegido legalmente. O processo termina com a inscrição no Livro de Tombo e 
comunicação aos proprietários. No Brasil, o órgão federal responsável pelo tombamento dos nossos bens culturais é o Iphan.

Cada Estado e Município também conta com órgãos próprios, responsáveis pelo tombamento de seus bens, como, por exemplo, o Conselho de Defesa do Patrimônio Histórico, Arqueológico, Artístico e Turístico - CONDEPHAAT, cuja finalidade é proteger, valorizar e divulgar o patrimônio cultural do Estado de São Paulo; e o Conselho Municipal de Preservação do Patrimônio Histórico, Cultural e Ambiental da cidade de São Paulo - Conpresp, órgão responsável pelo tombamento dos bens culturais da cidade de São Paulo.

Uma das formas de se avaliar e se decidir pelo tombamento de um bem cultural é a atribuição de valores. No entanto, determinar a qual valor o bem cultural está relacionado é uma tarefa bastante complexa. Para Fonseca (1997, p. 30):

Uma vez que as obras de arte são coisas às quais está relacionado um valor, há duas maneiras de tratá-las. Pode-se ter preocupação pelas coisas: procurá-las, identificá-las, classificá-las, conservá-las, restaurálas, exibi-las, comprá-las, vendê-las; ou, então, pode-se ter em mente o valor: pesquisar em que ele consiste, como se gera e transmite, se reconhece e se usufrui.

Na França do século XVIII o valor nacional, incontestavelmente, foi o que "inspirou, de ponta a ponta, as medidas de conservação tomadas pelo Comitê de Instrução Pública, quem justificou o inventário e o cotejo de todas as categorias heterogêneas da 'sucessão'" (CHOAY, 2001, p. 116). O valor nacional legitimou outros valores que vieram em seguida, como o valor cognitivo "que se subdivide em uma série de ramos relativos aos conhecimentos abstratos e às múltiplas competências" (CHOAY, 2001, p. 116); ou o valor econômico, pois "quase todos os textos salientam a importância, para atrair os visitantes estrangeiros, do patrimônio constituído pelos monumentos" (CHOAY, 2001, p.118). Por fim, o valor artístico, "condição compreensível numa época em que, salvo num meio culto e esclarecido, o conceito de arte ainda é impreciso e a noção de estética mal acaba de surgir" (CHOAY, 2001, p. 118).

Atualmente, pode-se dizer que o valor histórico ainda é de grande relevância como atributo para a preservação. Porém, o valor artístico, que antes estava em último lugar, hoje é visto com destaque entre os atributos da preservação.

O Iphan foi criado em 1937, inicialmente chamado de Serviço do Patrimônio Histórico e Artístico Nacional - Sphan, quando o então Ministro da Educação, Gustavo Capanema, com o intuito de institucionalizar a proteção ao patrimônio, recorreu a Mário de Andrade, por sua experiência no Departamento de Cultura da Prefeitura de São Paulo, a fim de que fosse elaborado um anteprojeto. Rodrigo Melo Franco de Andrade dirigiu o Sphan de 1936 a 1967. Diversas personalidades brasileiras fizeram parte de sua estrutura.

Classificar, segundo critérios sociais, os bens tombados pelo Sphan, ao longo de sua trajetória, causou algumas polêmicas. Segundo Fonseca (1997), inicialmente priorizou-se a arte colonial brasileira, principalmente 
devido ao processo de urbanização acelerado, quando diversos bens móveis eram saqueados e vendidos a colecionadores estrangeiros. Esses bens não eram valorizados pela classe média, que via neles a representação de uma cultura arcaica, simbolizada pela dominação portuguesa. Havia uma crescente valorização da cultura européia (inglesa e francesa) e da cultura norte-americana. No entanto, nada do que se referia à cultura indígena e negra foi preservado: "Afonso Arinos considerava que a presença portuguesa predominava sobre as influências negra e indígena, que praticamente não haviam deixado vestígios materiais significativos" (FONSECA, 1997, p. 118).

Dentre os elementos da arte colonial, a arquitetura religiosa constituía a grande maioria dos bens tombados, "justificada pelo lugar e pelo sentido que tinham as igrejas nas colônias luso-espanholas" (FONSECA, 1997, p. 119).

Havia certa prioridade em se preservar os bens arquitetônicos, tendo como justificativa a facilidade em investigá-los. Isso poderia ser reflexo da composição do corpo técnico da instituição, representado basicamente por arquitetos. "Os critérios adotados pelo Sphan eram sustentados não tanto por estudos e pesquisas, pouco acessíveis à opinião pública, mas pela autoridade dos agentes e da instituição que respondia pelos tombamentos" (FONSECA, 1997, p. 120).

Não se questionava o tombamento de determinados bens em detrimento do de outros, mas sim critérios de padronização para a execução do tombamento. Daí torna-se visível uma postura bastante inexpressiva do Sphan quanto à valorização do patrimônio como representativo de uma coletividade. $=$

Após o fim do Estado Novo, em 1945, a atuação do Sphan passou a ser questionada. As poucas renovações em seu quadro técnico acarretavam um desgaste muito grande na imagem da instituição. Diversas críticas relacionadas à degradação do patrimônio nacional eram enviadas aos jornais. Mister se fazia uma postura inovadora, que acompanhasse o momento de mudanças em que vivia o país.

A partir de 1965 o Sphan se espelhou na Unesco para reformular e respaldar sua atuação. "O objetivo era demonstrar a relação entre valor cultural e valor econômico, e não apenas procurar convencer autoridades e sociedade do interesse público de preservar valores culturais, como ocorrera nas décadas anteriores" (FONSECA, 1997, p. 160).

Por volta dos anos de 1970 a instituição passou a se chamar Instituto do Patrimônio Histórico e Artístico Nacional - Iphan. A partir desse momento o Iphan passou por profundas transformações, ampliou o número de diretorias regionais em todo o país, além de ter mudado sua política anterior, que só privilegiava o patrimônio arquitetônico, como podemos observar nas funções atribuídas ao Iphan:

I - executar, por intermédio das prefeituras, ou diretamente, o controle e a fiscalização dos conjuntos e núcleos tombados;

II - elaborar e propor o tombamento de bens culturais; 
III - exercer a fiscalização e a liberação de bens culturais;

IV - determinar o embargo de ações que contrariam a legislação em vigor;

V - executar diretamente a identificação, o cadastro, o controle e a fiscalização do patrimônio arqueológico em sua área de atuação;

VI - contribuir para a formulação da política de preservação do patrimônio cultural, propor normas e procedimentos e desenvolver metodologias, refletindo a pluralidade e diversidade cultural brasileira (BRASIL, 1990).

Segundo dados do próprio Iphan, hoje existem cerca de 16.000 edifícios tombados pela instituição, cinqüenta centros e conjuntos urbanos, 5.000 sítios arqueológicos cadastrados, mais de um milhão de objetos, 250 mil volumes bibliográficos, documentação arquivística e registros fotográficos, cinematográficos e videográficos. Atualmente um dos maiores desafios do Iphan tem sido compatibilizar a preservação do patrimônio cultural com as necessidades de desenvolvimento do país, o que implica na adequação da instituição às necessidades sócio-econômicas do Brasil.

\section{As bibliotecas tombadas pelo Iphan}

Quando voltamos nossa atenção para as bibliotecas, percebemos que ao longo do tempo elas nasceram e cresceram devido à relação que sempre se estabeleceu com o princípio de posse do objeto livro. Assim, diversas coleções foram formadas, sendo que suas transformações, deslocamentos e destruições determinaram a própria história das bibliotecas.

Diferentemente das coleções de objetos (cujos motivos são pessoais, portanto obscuros), as coleções de livros se sustentaram com base em dois princípios: o primeiro como símbolo de ostentação de poder e o segundo como desejo de reunir em um único espaço o maior conhecimento possível. Por esses motivos formaram-se as bibliotecas: lugares de ostentação e de criação de conhecimento, como foi o caso emblemático da Biblioteca de Alexandria, criada para a glória dos Ptolomeus e para reunir o conhecimento universal do Mundo Antigo.

No decorrer dos tempos, novas funções foram atribuídas às bibliotecas. As expropriações das bibliotecas reais e religiosas, durante a Revolução Francesa, possibilitaram a identificação da população com seus acervos e coleções, motivo para a criação de bibliotecas nacionais.

Já no século XIX, a biblioteca teve uma função pedagógica. Atrelada às escolas, serviu como auxiliar no aprendizado dos alunos, e serviu também para evitar desvios sociais, como foi o caso da criação da biblioteca pública inglesa, apontada como uma alternativa que evitava o alcoolismo do proletariado. 
Mas com a modernidade, iniciada pela sociedade industrial dos séculos XIX e XX, as bibliotecas assumiram um outro papel, o lugar de memória. Para tal, cabe utilizar o conceito de "lugar de memória" apontado por Nora (1993), para quem a sociedade contemporânea, havendo perdido os canais de memória que existiam na sociedade tradicional, tem de criar lugares nos quais essa memória seja preservada.

Não há como negar, hoje, o valor memorial, cultural e histórico das bibliotecas patrimoniadas e de suas coleções. Para Milanesi (2002, p. 9), "Essa atividade de buscar-o-que-foi-guardado e de guardar-o-que-foiregistrado (e de registrar-o-que-foi-imaginado) é a forma possível para manter viva a memória da humanidade, forma essa em constante aperfeiçoamento".

Já no caso da obra rara, Comitti (2000, p. 172) relata a importância do documento a ser preservado não só pelo seu valor de raridade, mas também pelo conteúdo informacional que muitos pesquisadores procuram: "[...] a quantidade de obras raras e de primeiras edições da virada do século XIX para o XX nos fornecem um rico material de pesquisa, não só para estudos de circulação de textos entre intelectuais do período, como também para subsidiar estudos de outros escritores, cujos livros são atualmente de difícil acesso".

Chagas (2002, p. 21) observa que a preservação de bibliotecas, arquivos e museus tem uma função social:

Elas apresentam-se como lugares onde determinados bens culturais são reunidos e preservados. A preservação, como foi visto, não dispensa o uso social. Em outros termos: museus, arquivos e bibliotecas guardam coisas, papéis, livros para serem usados por determinadas pessoas. Nos três casos, temos a identificação de usuários, tudo isso fazendo parte da mesma realidade e do mesmo processo histórico.

Camargo (1999, p. 50) fala da relevância de se preservar os centros de documentação, devido a seu valor histórico e informativo:

Tais centros apresentam como característica fundamental a proposta de trabalho que envolve a reunião, a preservação e a organização de arquivos e coleções (geralmente compostos de documentos originais, as "fontes primárias") e de conjuntos documentais diversos (de natureza bibliográfica ou arquivística, originais ou cópias) reunidos sob o critério do valor histórico e informativo, em torno de temas ou de períodos da história. Trabalha-se, portanto, com informação especializada.

Essa apreciação consiste no fato de que, além de ser lugar de memória, a biblioteca tem que ser resguardada também por ser "lugar de informação". 


\section{0 tombamento das bibliotecas brasileiras}

O levantamento das bibliotecas tombadas foi realizado no Arquivo Central do Iphan "Arquivo Noronha Santos", do qual se recuperaram nove itens. Após este levantamento, foi estabelecido um contato com o responsável pela Gerência de Documentação Arquivística e Bibliográfica do Iphan, a fim de confirmar se todas as nove bibliotecas levantadas poderiam fazer parte da pesquisa e se havia outras bibliotecas ou coleções que poderiam ser incluídas e que não tinham sido levantadas. Como resposta obteve-se a seguinte informação: dentre as nove bibliotecas, cinco delas não poderiam fazer parte da pesquisa, pois não tinham a função de biblioteca quando foram tombadas. Além disso, foram incluídas duas coleções bibliográficas que não haviam sido recuperadas na pesquisa feita no site do Arquivo Noronha Santos.

Sendo assim, delimitou-se o campo de estudo, trabalhando com quatro bibliotecas e duas coleções bibliográficas: Biblioteca Nacional: prédio - Rio de Janeiro/RJ, Capela da Venerável Ordem Terceira do Carmo - São Paulo/SP, Mosteiro e Igreja de São Bento - Salvador/BA, Biblioteca Antônio Torres - Diamantina/MG, Coleção Mário de Andrade do acervo do IEB-USP - São Paulo/SP e Sítio Roberto Burle Marx e sua coleção museológica e bibliográfica - Rio de Janeiro/RJ, que mais tarde se restringiram a apenas três bibliotecas.

Questionários foram elaborados, os quais foram enviados às bibliotecas e coleções tombadas. Para isso, foram necessários dois tipos de questionários, um para as bibliotecas e outro para coleções bibliográficas. O questionário para as bibliotecas contou com doze questões, abertas e fechadas. As perguntas foram baseadas em questões relativas à criação da biblioteca, ao processo de tombamento, ao acesso do público ao que foi tombado, ao acervo da biblioteca e à relevância do tombamento da biblioteca. O questionário para as coleções contou com onze questões, basicamente as mesmas feitas para as bibliotecas, mudando somente o enfoque.

Decorrido um mês após o envio dos questionários, não havia retorno das repostas. Novamente tentou-se entrar em o contato com as instituições, por telefone e e-mail, e a maioria alegou que não tinha condições de responder às questões propostas, pois não possuía informações suficientes. Então, optou-se por trabalhar diretamente com os processos de tombamento de cada instituição. Somente quatro processos estavam disponíveis para consulta, processo no 0079-T, referente ao Mosteiro e Igreja de São Bento - BA; processo no 0860-T-72, referente à Biblioteca Nacional: prédio - RJ; processo no 1176-T-85, referente à Capela da Venerável Ordem Terceira do Carmo - SP; e processo no 0429-T, referente à Biblioteca Antônio Torres - MG. Os processos no 1217-T-87 e 1131-T-84, referentes, respectivamente, à Coleção Mário de Andrade do acervo do IEB-USP - SP e ao Sítio Roberto Burle Marx e sua coleção museológica e bibliográfica, não se encontravam 
no Arquivo naquele momento. Daí a decisão de retirá-los do universo da pesquisa, já que não haveria informações suficientes para uma análise mais apurada.

A coleta de dados se deu a partir da leitura e gravação de trechos considerados pertinentes ao estudo em questão, já que não era permitida a fotocópia dos documentos. Em seguida, os trechos foram transcritos em sua forma original. Buscou-se, dessa forma, atender aos objetivos propostos, coletando dados que justificassem o tombamento das instituições analisadas, além de permitir a investigação do objeto tombado, ou seja, edifício ou coleção. Alguns processos atenderam fielmente às expectativas, trazendo informações valiosas, enquanto que outros nada diziam sobre o decorrer do tombamento.

Neste ínterim vieram as respostas dos questionários enviados à Biblioteca Nacional e à Biblioteca Antônio Torres. Também recebemos um manual da Capela da Venerável Ordem Terceira do Carmo com informações sobre o histórico da instituição, porém o questionário não foi respondido.

Mais tarde foi confirmado pelo Iphan que a Biblioteca Antônio Torres também não poderia fazer parte da pesquisa por ter sido criada após 0 tombamento da edificação em que ela se encontra.

A análise e a discussão dos dados foram feitas por meio da divisão dos dados coletados em quatro categorias: Site do Arquivo Noronha Santos; Processo de tombamento; Questionário e Informações da Instituição.

\subsection{Biblioteca Nacional (Rio de Janeiro - RJ)}

Segundo dados da Fundação Biblioteca Nacional (2004), no dia primeiro de novembro de 1755 Lisboa sofreu um grande terremoto, que destruiu parte da cidade. Como conseqüência, incêndios consumiram, principalmente, a parte velha da cidade, onde naquele momento se encontrava a Real Biblioteca, ou, como também era conhecida, Real Livraria.

Considerada uma das mais importantes bibliotecas da Europa, sua destruição representou uma perda irreparável para os lusitanos. Devido à sua suntuosidade, D. José I, imediatamente, começou a organizar uma nova biblioteca no Palácio da Ajuda, com a intenção de recompor aquela perdida.

A Real Biblioteca da Ajuda possuía um acervo preciosíssimo, com aproximadamente 60.000 exemplares entre livros, manuscritos, incunábulos, gravuras, mapas, moedas e medalhas. Este acervo foi trazido para o Brasil em três etapas, entre os anos de 1810 e 1811, pouco depois da transferência da família real para o nosso país, devido à invasão de Portugal pelas tropas francesas comandadas por Napoleão Bonaparte.

Inicialmente a biblioteca foi instalada no andar superior do Hospital da Ordem Terceira do Carmo. No entanto, essas acomodações se mostraram inadequadas para tão valioso acervo. No dia vinte e nove de outubro de 1810, data atribuída à fundação oficial da Biblioteca Nacional, 
o príncipe regente, D. João, determinou, por meio de um decreto, que a Real Biblioteca e os instrumentos de Física e Matemática fossem acomodados nas catacumbas dos religiosos do Carmo, ficando as despesas de arranjo e manutenção a cargo da Real Fazenda. Mas estas obras só foram concretizadas em 1813.

Em 1810 a consulta ao acervo era restrita aos estudiosos, com o consentimento régio. Já em 1814 a consulta foi aberta ao público.

O acervo da biblioteca foi sendo ampliado por meio de compras, de doações e principalmente das "propinas", ou seja, da obrigatoriedade da entrega de um exemplar de todo material impresso nas oficinas tipográficas de Portugal e na Impressão Régia, no Rio de Janeiro. Em 20 de dezembro de 1907, através do Decreto no 1825 , essa propina passou a ser chamada de Decreto de Depósito Legal, em vigor até os dias atuais.

Em 1821, quando o então rei $\mathrm{D}$. João retorna a Lisboa, deixa no Brasil a Real Biblioteca, que se tornou propriedade do Império do Brasil, por meio de compra, em vinte e nove de agosto de 1825. O valor pago pela biblioteca foi de 800 contos de réis. A Real Biblioteca passou a chamar-se Biblioteca Imperial e Pública da Corte.

Em 1858 a biblioteca foi novamente transferida para a Rua do Passeio, número 60, no Largo da Lapa, local que abriga hoje a Escola de Música da Universidade Federal do Rio de Janeiro.

Seu acervo ampliava-se a cada dia com a contribuição de doações, aquisições em leilão e em livreiros do mundo todo, além da contribuição legal. Essa ampliação crescente exigiu a construção de um espaço que pudesse melhor acomodar seu acervo. O prédio atual, possuindo características arquitetônicas em estilo eclético, foi projetado no governo de Rodrigues Alves, lançando-se a pedra fundamental em quinze de agosto de 1905. A inauguração se deu em vinte e nove de outubro de 1910, durante o governo de Nilo Peçanha.

Segundo consta no processo no 0860-T-72, referente ao tombamento da Biblioteca Nacional, o edifício arquitetônico da biblioteca, juntamente com os edifícios do Palácio Monroe, Tribunal da Justiça, Escola de Belas Artes, Derby Clube, Jóquei Clube, Clube naval e Teatro Municipal, representavam um conjunto precioso, que corria o risco de ser perdido devido a um arranha-céu que o Jóquei Clube tinha a intenção de construir no local onde se encontrava a sua sede e a do Derby Clube. A proposta de tombamento partiu do Clube de Engenharia, em apoio à manifestação feita pelo Instituto dos Arquitetos do Brasil. Recomendou-se que 0 conjunto fosse inscrito no Livro de Tombo Histórico. No dia vinte e quatro de maio de 1973 a Biblioteca Nacional foi tombada e inscrita no Livro de Belas Artes. No entanto, somente a edificação da biblioteca é tombada.

\subsection{Biblioteca do Mosteiro e Igreja de São Bento (Salvador - BA)}

A construção atual do Mosteiro é composta por três pavimentos e foi executada ao longo de quatro séculos. O projeto de construção do Mosteiro é atribuído ao Frei Macário de São João, que o iniciou no último 
quartel do século XVII. A igreja foi projetada em estilo neoclássico e ao longo dos anos sofreu a influência de diversas tendências e estilos.

A biblioteca do Mosteiro de São Bento da Bahia foi fundada em 1582, reunindo um acervo bibliográfico considerável, tanto em qualidade como em quantidade. Seu acervo conta com uma coleção de obras raras do século XVI, XVII, XVIII e XIX, composta por manuscritos, iluminuras, livros, documentos históricos, cartas, testamentos, mapas, desenhos e plantas de arquitetura, além de partituras musicais.

O Mosteiro e Igreja de São Bento da Bahia foram tombados no dia vinte e sete de junho de 1938 e inscritos no Livro de Belas Artes. Somente o prédio é citado no processo como bem tombado. No entanto, uma Resolução do Conselho Consultivo do Sphan de treze de agosto de 1985, referente ao processo administrativo no13/85/Sphan, considera que todo o acervo referente à igreja, ao mosteiro, ao convento e às capelas tombados seja considerado um bem patrimoniado.

\subsection{Biblioteca da Capela da Venerável Ordem Terceira do Carmo (São Paulo - SP)}

A edificação da capela, em estilo barroco, foi iniciada em 1632, sendo construída por partes e concluída em 1775.

No forro da capela-mor são encontradas obras do pintor Pedro Alexandrino (1730-1810); no forro da nave da Igreja aparecem as pinturas dos quatro evangelistas, dos doutores da Igreja e do Santos e Santas da Ordem Carmelita, obra de Padre Jesuíno do Monte Carmelo (1764-1818).

A igreja está ornamentada por onze luminárias de bronze, três grandes lampadários, castiçais, candelabros, credências, crucifixos e mobiliários trabalhados artisticamente à mão. Os forros da Biblioteca e da Sacristia foram pintados por José Patrício da Silva Manso e Padre Jesuíno Monte Carmelo, em 1799. A Igreja foi tombada no dia dezessete de maio de 1999 e inscrita no Livro de Belas Artes. No processo de tombamento não consta que o acervo da biblioteca foi tombado, somente um arquivo é citado como parte do tombamento. No entanto, a mesma Resolução do Conselho Consultivo do Iphan serviu para que o acervo bibliográfico fosse considerado um bem tombado.

\subsection{Os Processos}

Feita tal apresentação, pode-se observar que o tombamento da Biblioteca Nacional está restrito ao espaço construído e arquitetônico. Ou seja, apesar de possuir um acervo inegavelmente valioso e raro, este não está incluso no processo como bem tombado, não sendo, portanto, protegido pela legislação específica que visa à proteção dos bens tombados como patrimônio pelo Iphan.

O tombamento do prédio da Biblioteca Nacional é justificado pelas características arquitetônicas que o compõem, fazendo parte do seguinte conjunto de monumentos: Palácio Monroe, Tribunal da Justiça, Escola de 
Belas Artes, Derby Clube, Jóquei Clube, Clube Naval e Teatro Municipal. Segundo consta no processo, o tombamento do conjunto em detrimento de unidades isoladas era uma tendência moderna que seguia as recomendações da Carta de Veneza e da Lei Malraux.

Em relação à conservação do acervo de obras raras da Biblioteca, informações da própria Biblioteca Nacional mencionam a existência de um programa destinado exclusivamente ao tratamento de obras raras, chamado Plano Nacional de Recuperação de Obras Raras - Planor. No entanto, seu objetivo se restringe à orientação em relação aos procedimentos técnicos para organização, divulgação e preservação de acervos raros, oferecendo cursos, treinamento e assessoramento. Não há nenhuma lei que garanta a proteção deste acervo. O acesso aos acervos raros é restrito aos funcionários da Biblioteca Nacional, o que não impede que algum exemplar seja furtado, como já ocorreu, por não haver um sistema de segurança adequado.

Quanto ao Mosteiro de São Bento da Bahia, o alicerce construído segue a mesma linha dos monumentos da Ordem Beneditina, com inegável valor histórico e artístico. O Mosteiro representa a atuação do Iphan no início de suas atividades, ou seja, o tombamento de monumentos arquitetônicos representativos da Igreja Católica. Enfatiza-se a construção do Mosteiro, que durou quatro séculos (do século XVII ao $X X)$, sendo que a obra inicial era de autoria do Arquiteto Frei Macário de São João. O Mosteiro está inscrito no Livro de Belas Artes e seu tombamento aconteceu um ano após a criação do Iphan, em 1938.

Quanto ao acervo bibliográfico da Biblioteca do Mosteiro, pode-se considerar que ele está protegido pela Resolução do Conselho Consultivo do Iphan de treze de agosto de 1985. Segundo consta na Resolução, a proteção surgiu como conseqüência de freqüentes furtos ocorridos em igrejas tombadas no nosso país, além da venda de objetos valiosos que faziam parte do acervo destas igrejas, para o pagamento de dívidas da própria Ordem Religiosa. Como conseqüência desses fatos, optou-se pela criação de uma lei que garantisse a proteção de todo o acervo de igrejas, mosteiros, conventos e capelas tombados. Portanto, supõe-se que o acervo bibliográfico faça parte desse acervo protegido pela Resolução.

A Capela da Venerável Ordem Terceira do Carmo de São Paulo teve seu prédio tombado devido às características artísticas que compõe o seu interior, em especial as pinturas atribuídas ao Padre Jesuíno do Monte Carmelo e a José Patrício da Silva Manso. Além disso, diversos objetos decorativos (luminárias, lampadários, castiçais, credências crucifixos e mobiliários) enriquecem o acervo da Igreja. A Capela está inscrita no Livro de Belas Artes e no Livro Histórico. O valor histórico talvez se deva ao fato do arquivo da Capela estar incluído no processo de tombamento. Já o acervo da biblioteca da Capela não é citado no processo, apesar de possuir muitas obras raras. Conclui-se que a mesma Resolução do Conselho Consultivo do Iphan, de treze de agosto de 1985, protege o acervo bibliográfico da Biblioteca, seguindo as recomendações citadas anteriormente. 


\section{Considerações finais}

Conforme observado, o tombamento das bibliotecas analisadas reflete a atuação do Iphan no início de suas atividades, quando então recebeu inúmeras críticas por priorizar os monumentos arquitetônicos, principalmente os relacionados à Igreja Católica, em detrimento da cultura dita popular, ou seja, àquela com a qual grande parcela da população se identifica.

Percebe-se que a visão tradicional do tombamento da obra de arte esteve presente, a todo o momento, priorizando-se as artes maiores (arquitetura, pintura e escultura).

Houve a preocupação não só em se preservar o bem arquitetônico como lugar da memória ou lugar da memória física, representando a nação, como é o caso da Biblioteca Nacional e das ordens religiosas, por exemplo o Mosteiro de São Bento e a Capela da Ordem Terceira do Carmo, mas também como importância do edifício, como exemplo do tipo de arquitetura representativa da cidade em determinado momento histórico. No entanto, as coleções bibliográficas, suporte para informações do passado, que também fazem parte desta memória, não foram consideradas como bens passíveis de tombamento. Por isso, entende-se que as leis não consideram, explicitamente, os termos informação e memória, deixando assim, de preservar os seus suportes. Verifica-se que a informação, mesmo sendo um direito, não é considerada bem patrimonial.

No caso em questão, neste presente artigo, houve uma intencionalidade na construção de suas edificações, ou seja, foram construídas especificamente para abrigarem uma biblioteca. Portanto, mais do que nunca, a coleção bibliográfica deveria ser considerada no conjunto prédio-acervo bibliográfico.

Em nenhum momento houve a intenção de se tombar uma biblioteca. Tombou-se uma capela, um mosteiro e um conjunto de monumentos do centro do Rio de Janeiro que, por mero acaso, possuíam uma biblioteca. O tombamento das bibliotecas citadas foi apenas uma conseqüência do tombamento dos monumentos nos quais estavam inseridas.

Enfim, pode-se concluir que houve uma intensa desvalorização do bem cultural "acervo bibliográfico" no tombamento das bibliotecas analisadas. Em nenhum processo foi citado o termo "acervo bibliográfico" como bem passível de ser preservado pela Legislação de Proteção ao Patrimônio Histórico e Artístico em nível Federal. Em nenhum momento cogitou-se a preservação desse bem; nem mesmo em nossa Biblioteca Nacional, guardiã de toda a produção bibliográfica do nosso país, houve a intenção de se tombar as obras raras que fazem parte do seu acervo.

Assim, prevalece ainda o critério do edifício tombado e o esquecimento da coleção; mesmo considerando que a construção possa nos remeter à biblioteca como lugar da memória, seja no seu aspecto individual, pelos elos de lembrança que estabelecemos com o lugar, seja 
no seu aspecto da memória coletiva, a partir da qual a biblioteca se torna um lugar de identificação social.

No entanto, apesar do desenvolvimento nos últimos anos da Ciência da Informação, por um lado, e do patrimônio imaterial, por outro, vemos que ainda prevalece um total descaso com relação a estes aspectos que, como mencionado, merecem maior atenção dos pesquisadores da área.

\section{Referências}

BRASIL. Decreto 99.602 de outubro de 1990. Dispõe sobre a atuação no IPHAN - Instituto do Patrimônio Histórico e Artístico Nacional. Disponível em: <www.iphan.gov.br/legislac/decreto99602.htm>. Acesso em: 20 jul. 2004.

- Decreto-lei no 25 de 30 de novembro de 1937. Organiza a proteção do patrimônio histórico e artístico nacional. Instituto do Patrimônio Histórico e Artístico Nacional. Disponível em: <www.iphan.gov.br/legislac/decretolei25.htm> . Acesso em: 20 jul. 2004.

. Decreto no 3.551 de 04 de agosto de 2000. Institui o registro de bens culturais de natureza imaterial que constituem patrimônio cultural brasileiro, cria o Programa Nacional do Patrimônio Imaterial e dá outras providências. Instituto do Patrimônio Histórico e Artístico Nacional. Disponível em: <www.iphan.gov.br/legislac/decreto3551.htm>. Acesso em: 20 jul. 2004.

CAMARGO, C. R. Os centros de documentação das universidades: tendências e perspectivas. In: SILVA, Z. L. da. Arquivos, patrimônio e memória: trajetórias e perspectivas. São Paulo: Editora UNESP, 1999. p. 49-63. (Seminários e Debates).

CHAGAS, M. Cultura, patrimônio e memória. Revista Ciências e Letras, Porto Alegre, v.27, n.31, p. 15-29, jan./jun. 2002.

CHOAY, F. A alegoria do patrimônio. São Paulo: Editora UNESP, 2001. 282 p.

COMITTI, L. Acervos de escritores e preservação. Revista Ciências e Letras, Porto Alegre, v.25, n.27, p. 167-174, jan./jun. 2000.

CUNHA, M. C. P. Patrimônio histórico e cidadania: uma discussão necessária. In: O direito à memória: patrimônio histórico e cidadania. São Paulo: DPH, 1992. p. 9-11.

FENELON, D. R. Políticas culturais e patrimônio histórico. In: $O$ direito à memória: patrimônio histórico e cidadania. São Paulo: DPH, 1992. p. 2933.

FONSECA, M. C. L. O patrimônio em processo: trajetória da política federal de preservação no Brasil. Rio de Janeiro: UFRJ / IPHAN, 1997. 316 p.

FUNDAÇÃO BIBLIOTECA NACIONAL. Biblioteca Nacional. Disponível em: <www.bn.br> . Acesso em 15 maio 2004. 
INSTITUTO DO PATRIMÔNIO HISTÓRICO E ARTÍSTICO NACIONAL IPHAN. Tombamento. Disponível em: <http://www.Iphan.gov.br/ Iphan/tomb.htm>. Acesso em: 18 ago. 2004.

MILANESI, L. Biblioteca. Cotia: Ateliê editorial, 2002. 116p.

MILET, V. A teimosia das pedras: um estudo sobre a proteção do patrimõnio ambiental urbano. Olinda: Prefeitura de Olinda, 1988 apud FONSECA, Maria Cecília Londres. O patrimônio em processo: trajetória da política federal de preservação no Brasil. Rio de Janeiro: UFRJ / IPHAN, 1997. $316 \mathrm{p}$.

NORA, P. Entre memória e história: a problemática dos lugares. Projeto História: Revista do Programa de Estudos Pós-Graduados em História e do Departamento de História da Pontifícia Universidade Católica de São Paulo, São Paulo, v. 10, p. 07-28, dez. 1993.

POSSAMAI, Z. R. O patrimônio em construção e o conhecimento histórico. Revista Ciências e Letras, Porto Alegre, v. 25, n. 27, p. 13-24, jan./jun. 2000.

RHODEN, L. F. Legislação e inventários do patrimônio. Revista Ciências e Letras, Porto Alegre, v. 25, n. 27, p. 189-203, jan./jun. 2000. 